\title{
VARIETAL EFFECTS ON PRICE-SPREAD AND MILLING RECOVERY OF RICE IN NEPAL
}

\author{
Krishna P. Pant ${ }^{1}$ and Maniratna Aryal ${ }^{2}$
}

\begin{abstract}
General complaint of Nepalese farmers is that middlemen grasp much of the benefits from agricultural products paying low to farmers and charging high to the consumers thereby discouraging farmers to produce. Scientific studies are scanty to support or refute the complaint. The main objective of this paper is to test this hypothesis in light of rice recovery in milling. Primary data were collected from surveys of randomly selected 50 households and 41 mills from purposively selected 19 districts in Nepal. The study found that the rice recovery rate is $66.2 \%$ for head rice $73.2 \%$ for brown rice. After adjusting for the milling percent the retail price comes to be $14 \%$ to $18 \%$ higher than the farm gate price. The results show that the marketing margin is not so wide in case of less perishable crops like rice. Improving milling technology, however, can increase milling percent reducing the price spread.
\end{abstract}

Key words: Milling Recovery, Price Spread, Rice, Value addition

\section{INTRODUCTION}

Nepalese farmers are trying to leave their farm production mainly due to lower income from crop production than that from other employment. The low level of farm income which is the main reason of the detraction of the farmers is attributed to low farm gate price of their products. General complaint of the farmers is that middlemen grasp much of the benefits from agricultural products paying low to farmers and charging high to the consumers thereby discouraging farmers to produce. Scientific studies are very scanty to support or refute the claim. The producers in Nepal often complain that they are not getting their reasonable share of the consumers' rupee. At the same time, the consumers sometimes express their dissatisfaction in the way the products are retailed to them. In such cases, analysis of farm-retail price ${ }^{3}$ spread is a useful tool in assessing unfair pricing practices on marketing services, determining influential factors on marketing margin and estimating economic profit of dominant merchants (Shrestha, 2012). It is general perception that farmers are getting low price but consumers are paying high price for agricultural products. The nature of the price spread, however, differs from product to product depending on subsistence or luxury products and perishables or nonperishables.

Cereals and pulses are among the less perishable farm commodities. Among the cereals, rice is the most important one. It is the major staple crop in the country and nearly a half of the agricultural gross domestic product (AGDP) comes from rice alone. A widening of the marketing margin for rice could potentially discourage

\footnotetext{
${ }_{1}^{1}$ Agriculture Policy and Trade Expert, FAO, Nepal email:kpant@gmail.com

${ }^{2}$ Agricultural Economist, Market Research and Statistics Management Program, Lalitpur, Nepal

${ }^{3}$ Generally price means unique price at which buyers and sellers agree to trade in an open market at a particular time. In formal markets (such stock exchanges) there are two market prices: the offer (selling) price which is higher, and bid (buying) price that is lower. The difference between these two prices is called margin or spread.
} 
production and consumption making it a genuine concern for policy analyst. As the coarse and medium quality rice is a necessity to the consumers this study is focused on this staple food. Basmati and other aromatic rice are excluded from the study as they are luxury goods and their price depend more in the demand than in the costs of production.

More than a half of the world population eats rice as the main food in their daily diets. Rice is the major staple crop in Nepal that contributes about $50 \%$ to national food consumption. The terai region is suitable for rice production in terms of topography, irrigation facility and agro ecological factors. This area alone produces $75 \%$ of rice followed by $23 \%$ in the middle mountain and $2 \%$ in the high mountain (DOA, 2012). Surplus production in the terai is supplied to food deficit regions in the country. As the rice is mainly produced in terai region and consumed all over the country, rice marketing is important for regional distribution.

Rice is obtained from paddy after milling which removes husk and bran. The objective of the milling is to obtain whole grain rice and preserve most of the rice kernels in their original shape. The milling quality differs from variety to variety. Some varieties of rice do not yield much head rice (unbroken grains of milled rice) because of their inherent poor milling quality or due to the effects of climatic conditions or uneven processing practices. The recovery percentage of head rice is an indicator of quality of paddy rice. Higher the percentage of head rice indicates high quality, lower the head rice recovery and higher percentage of broken rice indicate poor quality.

In developing countries marketing system is generally imperfect and inefficient. Large number of scattered producers is involved in production and the entire population is the consumer. However, the traders involved in transferring the large chunk of these agricultural products to the consumers, especially at the wholesale level, are naturally much smaller as compared to the number of producers and consumers. The market imperfections increase price spread from the farm-gate to the consumers. The difference between consumer's and farmers' price is high in food commodities especially in the areas where inefficient marketing services and higher entrepreneurs profit exist. Timmer (1986) recognized this food price dilemma and attracted attention of producers, consumers, and policy analyst. It is obvious that the price spread depends mainly on the value addition along the value chain from the farm to the consumers. The value added can be in terms of form, space, time or exchange or any combination of them. Grading, cleaning, processing and packaging add value in terms of the form. Transportation increases value in terms space and storage increases the value in terms of the time. The exchange value comes from the transfer of the goods from one hand to other in the market. Understanding the value addition along the supply chain is important to understand whether the price spread is really justifiable or not.

Rice pricing is an important issue affecting farm income, food security and poverty alleviation. A few studies are available in price spread, marketing margins and costs of marketing and storage (Shrestha, 2012, Adhikari, 2011, Joshi et al., 2011). The information on value addition in terms of the form is very limited. In addition, the 
price spread and marketing studies are generally focused on fruits, vegetables and other cash crops (Pullabhotla et al., 2011). Such studies, however, very limited in less perishable farm products such as cereals and pulses.

It is reported that percentage of head rice depends on the different type of drying system and types of milling (Thapa et al., 2008). It is reported that most of the nutrients are concentrated in the outer layer of bran of the rice kernel which are lost during milling (Houston and Kohler, 1970). The loss of nutrients present may be reduced to a certain extent by low degree of polishing. It is also reported that breakage during polishing increases in the case of both raw and par-boiled rice although the increment is more rapid in raw rice (Rao et al., 1967). Growing population and rising income of the poor contribute in increasing the demand for rice. The main objective is to test the farmers' hypothesis that price spread is large to attract the black marketing act which prohibits a margin of more than $20 \%$. Specific objectives are to assess the milling recovery percentage of different varieties of paddy and analyze the price spread on rice marketing.

\section{METHODOLOGY}

The study is based on empirical analysis using primary and secondary data. The secondary sources include official crop data from Ministry of Agricultural Development and also from District Agriculture Development Office (DADO) of sample districts and Central Bureau of Statistics. Journal and seminar papers were other major secondary sources of information. The primary data were obtained through field survey of 19 districts in Terai (10) and hills (9). The sample districts were selected purposively based on the previous information on existence of different types of mills including huller, sheller and traditional pounding (dhiki). Among the sample districts, the terai districts were Chitwan, Rupandehi, Nawalparasi, Kapilbastu, Banke, Bardiya, Kailali, Dhanusa, Mahottari, and Morang, whereas the hill districts were Bhaktapur, Kavre, Nuwakot, Dolakha, Sindhupalchowk, Ramechap, Doti, Achham, and Dhading (Pant et al. 2013). Research sites in the sample districts were selected in consultation with District Agriculture Development Office (DADO) staffs taking criteria of coexistence of rice producing farmers' and different types of rice mills into consideration. Simple random sampling was used to select sample households and rice mills from the area where individual rice grower household and rice mill were sampling units. Altogether 50 farmers and 41 rice millers $(10 \%$ dhiki, $20 \%$ Huller and $70 \%$ Sheller mills) were interviewed. The primary data were collected from the sample households and rice mills using structured questionnaire and field observations. The farm gate price was obtained from the farmers' survey whereas the retail price of rice was obtained from the market survey in district headquarter.

The data were analyzed using statistical tools to estimate rice recovery rate and farm gate to retail price spread. Simple statistics like sum, mean, percentage, weighted average and standard deviation were used for descriptive analysis. Standard deviation and weighted average were used to validate the results obtained from analysis. The factors causing the low recovery of rice in milling were assessed by expert judgment. 


\section{RESULTS AND DISCUSSIONS}

\section{DESCRIPTION OF THE RESPONDENTS}

The results showed that $88 \%$ farmers and $95 \%$ mill holders are literate, higher than the national average of $66 \%$ literacy rate (CBS, 2011). This is mainly due to the nature of survey concentrated on farmers and mill holders having more education in order to extract the potentials of rice production, milling recovery and price spread more effectively. Average household size of rice farmers was found 7.42 which is quite higher than the national average of 4.88 persons per household (CBS, 2012). The average land holding size is $1.59 \mathrm{ha} /$ household, which is also higher than the national average of 0.68 ha (MoAD, 12). Joshi et al. (2011) also report similar figures. Over $61 \%$ of the holding size $(0.96 \mathrm{ha})$ is allocated to rice crop alone (Table 1$)$. This is mainly due to the nature of the sampling that purposively selected rice growing districts. The average holding of the irrigated land is 0.8 ha, i.e., $52 \%$ of land is under irrigation, which is similar to the national average of 54\% (CBS, 2011). The farmers are attracted to grow cash crops like tea, coffee, cardamom, offseason vegetables, fruits and ginger detracting them away from rice cultivation to a greater extent. The small size of holding with small scale production of rice limits the farmers from accessing the wholesale markets for fetching higher price. It is realized that the sample, however, includes larger proportion of the better off farmers than the national average.

Table 1. Descriptions of Respondents

\begin{tabular}{llccc}
\hline S.No. & Particular & Unit & Farmer & $\begin{array}{c}\text { Mill } \\
\text { Holder }\end{array}$ \\
\hline 1 & Literate & Percentage & 88.00 & 95.00 \\
& Illiterate & & 12.00 & 5.00 \\
2 & Family size & Numbers & $7.42 \pm 2.93$ & \\
3 & Total cultivated Area & ha & $1.59 \pm 1.40$ & \\
4 & Rice Cultivated Area & ha & $0.96 \pm 0.89$ & \\
\hline
\end{tabular}

Note: \pm represents standard deviation.

Source: Field survey 2013.

\section{FARM GATE AND WHOLESALE PRICE OF PADDY}

The results showed that average farm gate and retail price of paddy are Rs 20.39 and $22.90 / \mathrm{Kg}$ respectively with price spread of Rs 2.51 per $\mathrm{kg}$ (Table 2, Figure 1). Similar results are reported by Shrestha (2012). Variety-wise disaggregation of the price spread shows that the highest price spread was found in Taichung variety followed by Khumal 4 variety, whereas the smallest price spread was found in Krantibold variety and local rice. It's due to different levels of price paid depending on the choice based on consumers taste and preferences. Khumal 4 variety of rice with renowned aromatic variety Jethobudho as one of the parents is being sold in the market as a high quality rice zeera mashino. 
Table 2. Variety-wise average farm gate and retail price (Rs/Kg) of paddy

\begin{tabular}{clccc}
\hline S.No & Variety & Farm Gate Price & Retail Price & Price spread \\
\hline 1 & CH 45 & 20.25 & 23.00 & 2.75 \\
2 & Taichung & 27.33 & 31.33 & 4.00 \\
3 & Hardinath 1 & 18.00 & 20.00 & 2.00 \\
4 & Local & 24.50 & 26.42 & 1.92 \\
5 & Ram dhan & 20.25 & 23.50 & 3.25 \\
6 & OR & 20.25 & 22.25 & 2.00 \\
7 & Sabitri & 21.57 & 23.86 & 2.29 \\
8 & Megdut & 20.00 & 22.00 & 2.00 \\
9 & Krantibold & 15.50 & 17.00 & 1.50 \\
10 & Sawa & 20.00 & 22.00 & 2.00 \\
11 & Sarju 52 & 18.00 & 20.00 & 2.00 \\
12 & Chandina & 15.00 & 18.00 & 3.00 \\
13 & Khumal 4 & 26.00 & 29.50 & 3.50 \\
14 & Hybrid & 20.46 & 23.31 & 2.85 \\
15 & Sona Mansuli & 19.67 & 21.89 & 2.22 \\
16 & Jira Masino & 21.33 & 24.00 & 2.67 \\
17 & Radha 4 & 20.10 & 22.60 & 2.50 \\
18 & Makwanpur 1 & 17.50 & 20.25 & 2.75 \\
\hline & Simple & 22.39 & 22.90 & \\
& Average & 2.51 \\
\hline
\end{tabular}

Source: Field survey 2013.

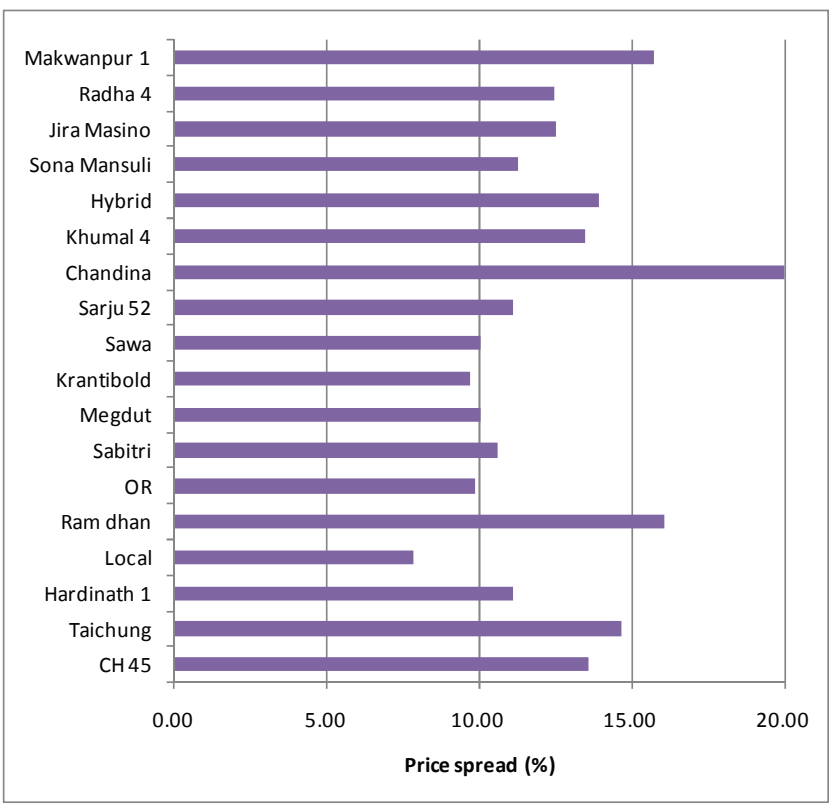

Figure 1. Farm gate to retail price spread of paddy by variety 


\section{PRODUCTIVITY OF DIFFERENT RICE VARIETIES}

Average paddy yield was $3.88 \mathrm{t} / \mathrm{ha}$ which is higher than the national average yield (3.33 t/ha) (MoAD, 2012). This may be due to the selection of study area having higher rice production potentials. Similar result was found by Joshi et al. (2011). The productivity of a crop depends on different climatic and non climatic factors, varietal characteristics, and management. Among 21 varieties of rice studied in the survey, the lowest productivity was for Jeera masino $(2.38 \mathrm{t} / \mathrm{ha})$ followed by local variety $(2.78 \mathrm{t} / \mathrm{ha})$; and the highest productivity was for hybrid variety $(6.62 \mathrm{t} / \mathrm{ha})$ followed by OR variety ( $5.33 \mathrm{t} / \mathrm{ha})$. Though some varieties of rice such as the Local have lower yield, fetch higher gross revenues because of their better taste, aroma and preference by consumers compared to other varieties.

\section{BROWN AND WHITE RICE RECOVERY PERCENTAGE}

Paddy is milled to remove the husk and the bran layers to produce ready to cook whole white rice kernels. The traditional technologies used for rice milling are foot pounding (dhiki) and hand pounding using mortar with a pestle (okhal). Although traditional technologies produce better quality rice, these, technologies are labour intensive and getting rare in recent years. Single pass rice mill, uses friction and very high pressure to remove the hull and polish the grain. However, it has lower white rice recovery rate as compared to two stage milling ${ }^{4}$. Average recovery of brown rice was found to be $73.2 \%$ which was aslower than other Asian countries (80\%) and developed (IRRI, 2010). The low recovery of brown rice may be due to rice variety, low level of irrigation, inappropriate post harvest handling, inadequate drying, unsuitable storage, milling, lack of skilled manpower for milling, and lack of advanced type of mills (Thapa et al., 2011).

The head rice recovery was found to be $66.2 \%$ with $3.4 \%$ of broken rice. Bran and husk content were found to be $5.9 \%$ and $24.6 \%$, respectively (Table 3 ). The head rice recovery rate was much lower in compare to other Asian countries (72\%) (IRRI, 2010, Malik and Majid, 1980).

\section{SEASONAL VARIATIONS IN PRICE OF PADDY AND MILLED PRODUCTS}

Seasonal price variations are affected by harvesting seasons and storage facilities. Storage losses and lack of trader participation in isolated markets affects seasonal price variations (Alderman and Shively, 1996).

\footnotetext{
${ }^{4}$ Two stage milling has separate hulling and polishing processes. Hulling removes the husk and the brown rice thus produced is then polished with a steel friction to produce white rice. Hulling gives brown rice with higher recovery rate whereas Sheller gives white rice with lower recovery. Different types of husking machines are available such as steel huller that removes the husks and whitens the rice in one pass, and 'under runner disc sheller' which first removes the husk leaving the brown rice kernel and then polices the kernel to give white rice. The brown rice is more nutritious than the white rice. Another type of huller is 'rubber roller huller' that reduces breakage of milled kernels (Teaching Manual on Rice Milling, IRRI).
} 
Table 3. White and Brown Rice Recovery Percentage from Sheller and huller type of mill

\begin{tabular}{clccccc}
\hline \multirow{2}{*}{ S. No } & Varieties & $\begin{array}{c}\text { Brown Rice } \\
\text { (\%) }\end{array}$ & \multicolumn{4}{c}{ White Rice } \\
\cline { 4 - 6 } & & & $\begin{array}{c}\text { Head Rice } \\
(\%)\end{array}$ & $\begin{array}{c}\text { Broken rice } \\
\text { (\%) }\end{array}$ & $\begin{array}{c}\text { Rice } \\
\text { Bran (\%) }\end{array}$ & Husk (\%) \\
\hline 1 & CH 45 & - & 64.00 & 3.00 & 6.00 & 27.00 \\
2 & Taichung & - & 68.00 & 3.33 & 5.83 & 22.83 \\
3 & Hardinath 1 & 71.00 & 64.00 & 4.00 & 5.00 & 27.00 \\
4 & Local & 74.00 & 66.29 & 3.29 & 5.43 & 25.00 \\
5 & Ram dhan & 73.00 & 63.75 & 3.25 & 6.75 & 26.25 \\
6 & OR & 72.00 & 64.33 & 3.67 & 6.00 & 26.00 \\
7 & Sabitri & 75.50 & 68.40 & 2.80 & 5.40 & 23.40 \\
8 & Krantibold & - & 71.00 & 3.00 & 6.00 & 20.00 \\
9 & Sawa & - & 66.00 & 4.00 & 6.00 & 24.00 \\
10 & Sarju 52 & - & 66.29 & 3.14 & 5.57 & 25.00 \\
11 & Khumal 4 & 73.00 & 65.63 & 3.25 & 5.50 & 25.63 \\
12 & Hybrid & 71.00 & 63.85 & 3.54 & 6.15 & 26.46 \\
13 & Sona Mansuli & 73.00 & 65.00 & 3.25 & 6.19 & 25.56 \\
14 & Jira Masino & - & 64.00 & 3.25 & 6.50 & 26.25 \\
15 & Radha 4 & 74.00 & 70.00 & 4.00 & 5.50 & 20.50 \\
16 & Makwanpur 1 & - & 64.50 & 3.83 & 5.67 & 26.00 \\
17 & Kanchan & - & 66.00 & 4.00 & 5.00 & 25.00 \\
18 & Bindeswori & - & 63.50 & 3.50 & 6.00 & 27.00 \\
19 & Gorakhnath & - & 66.00 & 3.00 & 6.00 & 25.00 \\
20 & Basmati & 75.00 & 63.00 & 3.20 & 6.40 & 28.40 \\
21 & Chandina & - & 70.00 & 3.50 & 6.20 & 20.30 \\
\hline Average & 73.15 & 66.20 & 3.40 & 5.90 & 24.60 \\
\hline Weighted Average & 73.05 & 66.08 & & & \\
\hline & & & & &
\end{tabular}

Source: Field survey 2013.

Farm gate prices of coarse and medium paddy were found Rs 20.72 and 24.29 per $\mathrm{Kg}$ respectively. It was the lowest in November (Rs $18.31 / \mathrm{Kg}$ ) and the highest in September (Rs 23.71/Kg) (Table 4). This result is similar to that found by Shrestha (2012) (Farm gate: Rs19.49/Kg, Wholesale: Rs $26.65 / \mathrm{Kg}$ and Retail Rs $30.23 / \mathrm{Kg}$ ). November is the harvesting season for rice lowering the farm gate price. Farmers find difficulties to store for future expected higher price due to limited storage facilities, problem of storage pests; and also have to sell at the time of harvest to repay loans which is the major source of funding to manage the family expenditure.

The yearly average price of the white rice was found to be Rs 35.77 and $43.50 / \mathrm{Kg}$ for coarse and medium varieties respectively. Broken rice, bran and husk have the mill gate price of Rs 20.52, 18.22 and $1.95 / \mathrm{Kg}$, respectively (Table 4). Pattern of price fluctuation was found similar with the paddy, higher at September and lower at November by its nature of supply fluctuations. 
Table 4. Monthly farm gate price of paddy and retail prices of head rice, broken rice, bran and husk (2012)

\begin{tabular}{|c|c|c|c|c|c|c|c|c|}
\hline \multirow[t]{2}{*}{ S.No } & \multirow[t]{2}{*}{ Months } & \multicolumn{2}{|c|}{$\begin{array}{l}\text { Farm gate price } \\
(\mathrm{Rs} / \mathrm{Kg})\end{array}$} & \multicolumn{5}{|c|}{ Retail Price of milled products (Rs/Kg) } \\
\hline & & $\begin{array}{l}\text { Coarse } \\
\text { Paddy }\end{array}$ & $\begin{array}{l}\text { Medium } \\
\text { Coarse } \\
\text { Paddy }\end{array}$ & $\begin{array}{c}\text { Coarse } \\
\text { Rice }\end{array}$ & $\begin{array}{l}\text { Medium } \\
\text { Rice }\end{array}$ & $\begin{array}{c}\text { Broken } \\
\text { Rice }\end{array}$ & Bran & Husk \\
\hline 1 & November & 18.31 & 21.81 & 32.06 & 40.09 & 18.97 & 16.88 & 1.81 \\
\hline 2 & December & 18.55 & 21.97 & 33.29 & 40.13 & 19.00 & 16.85 & 1.80 \\
\hline 3 & January & 19.04 & 22.29 & 33.97 & 40.81 & 19.28 & 16.85 & 1.80 \\
\hline 4 & February & 19.94 & 23.45 & 35.03 & 42.19 & 19.81 & 17.46 & 1.77 \\
\hline 5 & March & 20.19 & 23.84 & 35.60 & 43.00 & 20.06 & 17.99 & 1.80 \\
\hline 6 & April & 20.64 & 24.13 & 35.91 & 43.63 & 20.53 & 18.40 & 1.89 \\
\hline 7 & May & 21.46 & 24.61 & 36.54 & 44.78 & 21.19 & 18.59 & 2.02 \\
\hline 8 & June & 21.79 & 25.52 & 37.76 & 45.22 & 21.31 & 19.10 & 2.05 \\
\hline 9 & July & 22.77 & 26.45 & 38.34 & 46.34 & 21.81 & 19.53 & 2.19 \\
\hline 10 & August & 23.53 & 27.00 & 38.71 & 47.63 & 22.16 & 19.94 & 2.19 \\
\hline 11 & September & 23.71 & 27.65 & 39.06 & 48.00 & 22.63 & 20.06 & 2.23 \\
\hline \multirow[t]{2}{*}{12} & October & 18.69 & 22.81 & 32.94 & 40.19 & 19.50 & 17.00 & 1.93 \\
\hline & Average & 20.72 & 24.29 & 35.77 & 43.50 & 20.52 & 18.22 & 1.95 \\
\hline
\end{tabular}

Source: Field survey 2013.

Most of the traders and private mill owners purchase paddy at the time of harvest with lower price, store in their own storage and supply milled rice at the time of shortage with higher price. The moisture percent of the rice decreases during the storage. The stored or aged rice is preferred by the consumers due to its better cooking quality. On the basis of taste preference and aroma, the farmers are cultivating local rice varieties and such varieties also fetch higher gross revenue even the yield is low.

The profit margin gained by traders and middlemen after value addition by deducting marketing cost is found $25 \%$ compared to rough rice marketing. This percentage of profit is higher than normal. If we can increase marketing efficiency of the farmers and minimize the profit margin of the traders down to $10 \%$ which is reasonable in case of non perishable commodity, the remaining 15\% can go either to the consumers or the producers. One of the factors affecting the price spread on rice is the storage problem. The farmers are unable to store the rice for lean season due to limited storage facilities, and related problem of storage pests. Some farmers are indebted during festival seasons and have to sell their produce at the time of the harvest to repay loans.

\section{FACTORS AFFECTING THE RICE RECOVERY PERCENTAGE}

Rice recovery percent from hulling and milling are lower in Nepal than in other countries. Increasing the milling percent is crucial for reducing the farm gate to retail price spread in rice and increasing the efficiency of rice marketing. Reducing the ratio of the broken rice is necessary for exporting of rice. Some major factors affecting the head rice recovery are discussed in the following paragraphs. 


\section{Varietal characteristics}

As discussed earlier varietal characteristics affect the rice recovery. Grain size and shape (length-width ratio) is the varietal property affecting the milling percent. Long slender grains normally have greater chance of breakage than short, bold grains and consequently have a lower milled rice recovery. Up to $5 \%$ broken rice is allowed in international trade of Basmati rice with some compromise to the price.

\section{Harvesting time, threshing and drying}

Harvesting time and moisture content in the rice affect recovery percent. Immature harvesting, uneven drying and improper setting of threshing machine reduce the recovery (Table 5). The immature rice kernels are very slender and chalky and this results in excessive production of bran, broken grains and brewer's rice5. The optimal stage to harvest grain is at about $20-25 \%$ grain moisture or about 30 days after flowering. The grains harvested at right time, with lower moisture content and suitable machine give better recover percent.

Moisture content

Moisture content has a marked influence on all the aspects of paddy and rice quality and it is essential that paddy be milled at the proper moisture content to obtain the highest head rice recovery. All the varieties of paddy are at its optimum milling potential at moisture content of $14 \%$ wet weight basis (Malik and Majid, 1980). Grains with high moisture content are too soft to withstand hulling pressure which results in grain breakage and possibly pulverization of the grain. Grain that is too dry becomes brittle and has greater breakage. Moisture content and temperature during the drying process is also critical as it determines whether small fissures and/or full cracks are introduced into the grain structure.

Table 5. Minimum Standard of harvested and threshed paddy

\begin{tabular}{lll}
\hline Operation & Desired moisture content (\%) & Primary cause of losses \\
\hline $\begin{array}{l}\text { Mechanical } \\
\text { threshing }\end{array}$ & $20-25$ & $\begin{array}{l}\text { Shattering if grain is too dry } \\
\text { Incomplete threshing, spillage, grain damage } \\
\text { and cracking }\end{array}$ \\
Hand threshing & $20-25$ & $\begin{array}{l}\text { If drying is delayed: spoilage, fungal damage, } \\
\text { discoloration, smell, loss of vigor }\end{array}$ \\
Drying & - Moisture $<14 \%$ for grains & \\
& $\bullet<13 \%$ for seeds & \\
& $-<9 \%$ for long-term storage & \\
\hline
\end{tabular}

Source: Rice Science for Better World, IRRI, 2003

\footnotetext{
${ }^{5}$ Broken pieces of food-grade rice used in the manufacture of food, feed and beverages.
} 


\section{Degree of purity}

Purity is related to the presence of dockage in the grain. Dockage refers to material other than paddy and includes chaff, stones, weed seeds, soil, rice straw, stalks, etc. These impurities generally come from the field or from the drying floor. Unclean paddy increases the time taken to clean and process the grain and also decreases the head rice recovery.

\section{Varietal purity}

A mixture of different varieties of rice with different sizes of grains causes difficulties at milling and usually results in reduced capacity, excessive breakage, lower milled rice recovery and reduced head rice. Different sizes and shaped grains make it more difficult to adjust hullers, whiteners and polishers to produce whole grains.

\section{Cracked grains}

Overexposure of mature paddy to fluctuating temperature and moisture conditions leads to development of fissures and cracks in individual kernel. Cracks in the kernel are the most important factor contributing to rice breakage during milling reducing the head rice recovery.

\section{Yellowing}

Yellowing is caused by over-exposure of paddy to wet environmental conditions before it is dried. This result in a combination of microbiological and chemical activity that overheats the grain leading what locally know as hakuwa. These partially fermented grains frequently possess partly gelatinized starch cells and generally resist the pressures applied during grain milling. While the presence of fermented grain does not affect milling yields it does downgrade the quality of the milled rice because of the unattractive appearance and bad smell during cooking.

\section{Operators' skill, type of machine and power cut}

If the rice mill operator is more skillful in milling process, higher recovery rate is possible. The head rice recovery also depends on the type of hulling and shelling machines used for rice milling. Modern machines are developed with higher recovery rate reducing the losses in milling process. The frequent power cuts cause difficulties in appropriate handling of the machine decreasing the life of the machine as well as the rice recovery.

\section{CONCLUSION}

Average paddy yield is found $3.88 \mathrm{t} / \mathrm{ha}$ which is slightly higher than the national average yield (3.30 t/ha). Average rice recovery percentage of brown rice was found to be $73.2 \%$ which is lower than that in other developed and Asian countries with $80 \%$ (IRRI, 2010). Head Rice Recovery percentage is found $66.2 \%$ that excludes broken rice. Average farm gate and retail price of paddy are Rs 20.39 and Rs 22.90 per $\mathrm{Kg}$, respectively. The average price of the milled white rice is found to be Rs 35.77 and 
43.50 per $\mathrm{Kg}$ for coarse and medium varieties, respectively. Broken rice, bran and husk have the mill gate price of Rs 20.52, 18.22 and 1.95 per kg respectively. The highest price spread is found in Taichung followed by Khumal 4.

Among milling technologies huller mill gives more nutritious brown rice with higher recovery percent, whereas, sheller mill produces white polished less nutritious rice with lower recovery percent. Though the traditional technologies for rice milling such as foot pounding and hand pounding produce better quality rice they are labour intensive and becoming rarer in recent years. Other major factors causing lower head rice recovery percentage are low quality rice variety, inadequate skills of the mill operators, unsuitable mills, frequent power cuts, inadequate drying and threshing facilities for the paddy and the varieties used.

Rice being a less perishable commodity, the price spread is not so high as generally thought to be. The small size of holding with small scale production, however, limits the farmers from accessing the better markets for paddy for fetching better price. Development of warehousing facilities in major rice growing regions can save the farmers from distress selling of rice at glut season. Rice recovery percent is much lower in Nepal as compared to other countries increasing inefficiency in rice value chain. Millers need advanced milling equipments and careful handling to increase rice recovery. At the same time, skill development in rice milling is equally important. Improving milling technology can increase milling percent reducing the price spread. Besides this, we should educate our consumers to consume more nutritious brown rice with higher recovery rate than the less nutritious white rice with lower recovery rate.

\section{ACKNOWLEDGEMENT}

Authors are thankful to Mr. Netra Bhandari, Mr. Kishor Parajuli and Mr. Gokarna Sharma, senior/officers in Market Research and Statistics Management Programme, Department of Agriculture for their support during data collection and compilation for this study.

\section{REFERENCES}

Adhikari, R.K., 2011. The Journal of Agriculture and Environment. Vol.12., MOAC, Kathamndu. Alderman, H., Shively, G.E., 1996. Economic Reform and Food Prices: Evidence from Markets in Ghana. World Development, Vol. 24 (3), pp 521-534.

CBS, 2011. National Sample Census of Agriculture, Nepal (2010/2011). District Summary. Kathmandu: CBS.

CBS, 2012. National Population and Housing Census (2011). National Planning Commission Secretariat. Kathmandu: CBS.

Houston, D.F. and G.O. Kohler. 1970. Nutritional properties of rice. National Academy of Sciences, Washington D.C.

IRRI. 2010. Rice marketing system in Nepal. Final Report, IRRI, Los Banos, Philippines.

Joshi, N.P., Maharjan, K.L., and Piya, L. 2011. Production Economics of Rice in Different Development Regions of Nepal. Journal of International Development Cooperation. Vol.17. Japan.

Malik, A., A. Majid and S. Ahmad, 1980. Effect of different moisture levels and variety on milling quality of rice. Pakistan Journal Agricultural Research, Vol. 1 No.2. 
Malik, M.A. and A. Majid., 1973. Studies on Milling of rice (Oryza sativa L.). Proceedings of Seminar on Rice Production held at Dokri, Sind. 14-15 March, 1973. pp. 380-383.

MoAD, 2012. Ministry of Agriculture Development, 2012. Statistical Information on Nepalese Agriculture. Kathmandu: Ministry of Agricultural Development.

Pant, K. P., Bhandari, N. B., Parajuli, K., Sharma, J. and Aryal, M. 2013 Price Escalation along the Value Addition on Paddy, a report, Market Research and Statistics Management Program, Lalitpur, accessed from http://www.agribiz.gov.np on 6 May 2014.

Pullabhotla, H., Shreedhar, G., Kumar, G.A., Gulati, A., 2011. A review of input output policies for cereal production in Nepal. IFPRI discussion paper. International Food Policy Research Institute, New Delhi.

Rao, R., Narayana, M. N., Desikachar, H. S. R. 1967. Studies on some comparative milling properties of raw and parboiled rice. Journal of Food Science and Technology, 4(4):150155.

Shrestha, R.B., 2012. Factors affecting price spread of rice in Nepal, The Journal of Agriculture and Environment. Vol.13. Ministry of Agriculture and Cooperatives. Kathamndu, pp 47-52.

Thapa, M.J., Shrestha M.B., Karki, R. and Bhattarai, C.M., 2011. Study on quality and milling recovery of different varieties of rice at varying degree of polishing under Khumaltar condition. Agronomy Journal of Nepal, Vol. 2: 2011, pp 88-92.

Timmer, C. P. 1986. Private Decisions and Public Policy: The price dilemma in food systems of developing countries, Michigan State University (MSU) International Development Paper 7, pp 1-49. 